\title{
1 Using camera traps to determine occupancy and breeding in burrowing
}

2

3

\section{Authors}

5 Jeremy P. Bird ${ }^{1,2}$, Richard A. Fuller $^{1}$, Penny P. Pascoe ${ }^{2}$, Justine D. S. Shaw ${ }^{1}$

7

\section{seabirds}

\author{
6 1. School of Biological Sciences, University of Queensland, Brisbane, QLD 4072, Australia
}

2. Institute of Marine and Antarctic Studies, University of Tasmania, 20 Castray Esplanade, Battery

Point, TAS 7004, Australia

\section{Corresponding author}

Jeremy P. Bird - jez.bird@uq.edu.au

\section{ABSTRACT}

Burrowing seabirds are important in commercial, ecological and conservation terms. Many

populations are in flux owing to both negative and positive anthropogenic impacts, but their ecology makes measuring changes difficult. Reliably recording key metrics, the proportion of burrows with breeding pairs, and the success of breeding attempts, requires burrow-level information on occupancy. We investigated the use of camera traps positioned at burrow entrances for determining the number of breeding pairs in a sample to inform population estimates, and for recording breeding success. Linear Discriminant Analyses of time series activity patterns from camera traps successfully partitioned breeding and non-breeding burrows at different stages of the breeding season and had reasonable predictive ability to determine breeding status on a small test dataset. Compared with 
23 traditional techniques for determining burrow occupancy (e.g. manual burrow inspection and

24 playback of conspecific calls at burrow entrances), camera traps can reduce uncertainty in estimated

25 breeding success and potentially breeding status of burrows. Significant up-front investment is

26 required in terms of equipment and human resources but for long-term studies camera traps can

27 deliver advantages, particularly when unanticipated novel observations and the potential for

calibrating traditional methods with cameras are factored in.

\section{INTRODUCTION}

Seabirds are a major component of marine food webs consuming prey volumes commensurate with commercial fisheries (Barrett et al., 2006; Danckwerts et al., 2014). In the Southern Oceans one taxonomic group, the Procellariiform petrels, is second only to penguins in terms of avian biomass

34 (Catry et al., 2003) and volume of prey consumed (Croxall et al., 1984). By transferring nutrients from pelagic to marine and coastal ecosystems, petrels make significant contributions to global geochemical cycles (Otero et al., 2018). These inputs, together with soil modification from their burrow-nesting habit result in positive influences on island biodiversity (Graham et al., 2018; Sekercioglu, 2006). However, petrels are also highly susceptible to invasive predators which have precipitated catastrophic declines in many populations resulting in 45 of 97 species (46\%) being threatened with extinction (BirdLife International, 2018; Croxall et al., 2012; Dias et al., 2019). occurrence, nocturnal activity at colonies and challenges in finding, counting and ascertaining the contents of burrows all contribute to high levels of uncertainty when populations are assessed (Bird et al., submitted; Rodríguez et al., 2019). The most important metrics for tracking conservation status and population-level responses to impacts are the number of breeding burrows and their success rate, both of which rely upon one-off, or repeat measures of burrow occupancy. 
In recent years, audio playback for small species and manual burrow inspections for larger species

have emerged as the most widely used occupancy detection methods in burrowing seabird studies

(Bird et al., submitted). Playback requires calibration to account for non-responsive birds (Soanes et colonies (Carey, 2009). To meet ethical guidelines and ensure data is representative of natural prevalent, but accuracy is highly variable according to the quality of equipment available (Carlile et al., 2019; Lavers et al., 2019). Manual burrow inspection is also labour intensive, and repeat visits to measure breeding success still have uncertainty around outcomes when burrows change from occupied to empty between visits. 
species, but their use in studies of burrowing seabirds has mainly been limited to understanding the suitability of camera traps for studying diving-petrels Pelecanoides spp. by pairing them with breeding biology in diving-petrels.

There has been no test of whether continuous observations using camera traps can overcome shortcomings of playback and manual burrow inspection. Unlike playback no calibration is required, and long-term deployments could reveal outcomes of breeding events in individual burrows with higher resolution than intermittent manual inspections. If so, camera traps have the potential to considerably improve burrowing seabird conservation assessments providing reliable information with low uncertainty on occupancy, the proportion of burrows occupied by breeding pairs, and breeding success. of burrowing petrel on sub-Antarctic Macquarie Island. We assess the performance of cameras for: i) recording nest-level activity; ii) recording breeding success rate; and iii) inferring the ratio of breeding to non-breeding burrows. Finally, we compare the results from camera traps with traditional playback and burrow-inspection methods. 
97 Macquarie Island $\left(54^{\circ} 30^{\prime} \mathrm{S}, 158^{\circ} 57^{\prime} \mathrm{E}\right)$ has many of the characteristics that make surveying and

98 monitoring burrowing petrels challenging. Lying approximately $1,500 \mathrm{~km}$ south-east of Tasmania,

99 almost midway between Australia and Antarctica, it is remote and therefore costly to visit. The

island's status as a UNESCO World Heritage Site and Tasmanian Nature Reserve means invasive

research activities and visitation are restricted. It is 12,785 ha in area, $34 \mathrm{~km}$ long and up to $5 \mathrm{~km}$

wide, rugged with sections of coastal cliffs and a steep escarpment rising to an upland plateau

reaching $400 \mathrm{~m}$ above sea level. The sub-Antarctic climate and potential for extreme weather

conditions (Adams, 2009; Pendlebury and Barnes-Keoghan, 2007), the terrain, and the limited access

to medical facilities mean strict health and safety protocols are in place to protect personnel, and

slopes and fact that vegetation communities are recovering following decades of impacts by

European Rabbits Oryctolagus cuniculus (Springer, 2016) all make finding and studying seabird

110 is challenging.

111 Our study addressed two large-bodied species: Grey Petrel Procellaria cinerea $(950-1,220 \mathrm{~g})$ and

112 White-headed Petrel Pterodroma lessonii (750-780 g); and two medium-bodied species: Blue Petrel

113 Halobaena caerulea (171-253 g) and Antarctic Prion Pachyptila desolata (116-160 g; Jouventin,

114 1985). All four species nest in burrows dug predominately in peat substrate.

115 Constraints on the location and timing of fieldwork meant we were unable to compare all burrow 
120 Six Reconyx HC600 trail cameras were deployed at the entrance to Grey Petrel burrows from $10^{\text {th }}$

121 June 2017 to $22^{\text {nd }}$ November 2017. In 2018, six Reconyx HC600 and four Spypoint Force 10 trail

122 cameras were deployed outside Grey Petrel burrows from $1^{\text {st }}$ April to $2^{\text {nd }}$ November (Figure 1).

123 Twenty Spypoint Force 10 cameras were deployed outside Blue Petrel burrows from $15^{\text {th }}$ August

1242018 to $4^{\text {th }}$ February 2019 (see Figure S1-5 for burrow identification). Cameras were all set to 'high'

125 sensitivity, to take three images per trigger with 1 second interval between, and no delay between

126 triggers. They were checked at intervals to replace batteries and memory cards.

We tagged all images manually in ExifPro 2.1.0 (http://www.exifpro.com/index.html), discarding any

images associated with camera set-up. We tagged images that featured a bird with the species, the

number of individuals (rarely $>1$ ), and whether there was a chick. We also tagged behaviours:

burrow entries, exits and tidying of the burrow entrance which appeared to be associated with

131 breeding.

132 To assess camera performance, we recorded periods of camera inactivity, we compared the total

133 numbers and ratios of false triggers to target triggers, the mean numbers of events per day between

134 cameras, and the ratio of entries to exits. For behavioural analysis, we grouped images into

135 'events' - series of consecutive images separated by no more than 5 minutes. We plotted the

number of events per day against date for both adults and chicks. We relabelled entries and exits as

137 'transits' and plotted the total per day against date, together with the number of tidying events

recorded.

We manually inspected all Grey Petrel burrows with camera traps at the entrance four times during

140 the period over which cameras were deployed (5 months in 2017 and 7 months in 2018) to

141 determine breeding status and breeding success at the burrow. To understand whether adult

142 activity patterns derived from the cameras could be used to reliably infer breeding status of burrows

143 we derived test variables: mean number of events, duration of absences in days, the proportion of

144 days where high activity was recorded (> 5 events), and the proportion of days where low activity 
145 was recorded (1-5 events). We derived these variables for each stage of the breeding season:

146 incubation, early chick-rearing and late chick-rearing (fledging was dropped owing to low adult

147 activity). We tested for correlation between the variables by dropping one of a pair of variables if

148 their $r^{2}$ was $>0.6$, and then used principal component analysis (PCA) to look for patterns in our data.

149 Then we classified breeding and non-breeding burrows using linear discriminant analysis (LDA). PCAs

and LDAs were performed for each breeding stage. Because our burrow sample was small, we used

all full-season time series to build the LDA models. We derived a test dataset from cameras that

malfunctioned during the season for which only partial time-series were available and used these to

Playback and burrow inspection

Both playback and manual burrow inspection have been used to determine occupancy of Grey

Petrel, Antarctic Prion and Blue Petrel burrows (Barbraud et al., 2009; Brothers and Bone, 2008;

Dilley et al., 2017). However, Pterodroma petrels vocalise during aerial displays at night, but rarely

respond from the nest chamber to stimuli during the day, so manual inspection is required for 
handheld Canon Powershot camera held at arm's length down the burrow to calibrate the two

methods and allow correction of data from previous years when cameras were used. We checked

242 Grey Petrel burrows by handheld camera or burrowscope, and 247 Blue Petrel and 76 Antarctic

Prion burrows with the burrowscope. A burrow was recorded as 'empty' when the observer believed

they could see the end of the burrow and any side chambers were visible in images, or 'uncertain' if

the end was not visible. In occupied burrows we noted the number and identity of adult birds, eggs, and chicks.

We revisited burrows to check breeding status and the outcome of breeding attempts through the season. All burrows in which eggs, recent eggshell or chicks were found in the burrow or at the entrance were recorded as breeding burrows. If adults were present during the first visit but not subsequently the breeding status was 'uncertain'. Burrows with adults present later in the season were recorded as non-breeding. The repeat visits were used to calibrate earlier visits-the status of burrows labelled originally as 'uncertain' often became clear on second or third visits, and we estimated our type 1 error rate by identifying breeding burrows originally labelled as 'empty'.

For comparison with occupancy and uncertainty estimates from our initial burrow inspections we used playback for both medium-sized species. Playback provides information on the proportion of burrows occupied, relying on birds responding when a recording of a conspecific vocalising is played near their burrow entrance. It is common in studies of small-bodied species whose burrow entrances are small, precluding manual inspection (Perkins et al., 2018). Response rates are known to vary so following Soanes et al. (2012) we repeated playback 4 times to a sample of 61 Antarctic Prion sample with confidence limits (du Feu et al., 1983). 
195

196

197

198

199

200

201

202

203

\section{Recording nest-level activity and breeding success from cameras}

Overall camera traps proved to be very effective. The expected target species was recorded on all cameras placed at burrow entrances. One camera placed at a burrow entrance for a night equates to one 'trap night'. We recorded 47,179 images of Blue Petrels during 3,554 trap nights, and 42,705 images of Grey Petrels during 2,677 trap nights. However, performance varied greatly between the two types of cameras we deployed. The ratio of target triggers to false triggers was much higher for Reconyx cameras compared with the SpyPoint cameras, and the proportion of trap nights where $>0$ images were captured, i.e. the camera was known to be recording, was also higher (Table 1). In reality, short periods of several days where no images were captured are likely to reflect genuine absences of activity, whereas long periods (e.g. >10 days) with no target or false triggers likely reflect camera malfunction, especially in SpyPoint cameras given their high false trigger rate. Although we primarily deployed Spypoint cameras at Blue Petrel burrows and Reconyx at Grey Petrel burrows, the relative differences in performance are still apparent in the one Reconyx camera at a Blue Petrel burrow and the four SpyPoint cameras at Grey Petrel burrows (Table 1). Overall SpyPoint cameras were far more likely to be triggered when no animal was present, and there were many more days, irrespective of species, when the cameras did not record any images.

Despite the stark difference in camera performance, we recorded specific behaviours at all burrows such as entries and exits, digging, tidying at burrow entrances, chicks emerging and exercising, predators (Brown Skua Catharacta antarctica) and competitors entering burrows (e.g. Antarctic Prions in Blue Petrel burrows and Sooty Shearwaters in Grey Petrel burrows; Figures S7-8). While we were interested in burrow-level variation in behaviours recorded, the variance in certain behaviours, for example the ratio of entries to exits, suggests that positioning of cameras has an important bearing on what is recorded. Some cameras recorded five times more entries than exits, while others recorded five times more exits than entries (Table 1). 
219 While camera make and positioning influenced the type and level of activity recorded at each

220 burrow, averaging activity by classifying events and specific behaviours, both makes of camera

221 provided season-long activity signatures for many burrows (Figures 2 and 3 ). The mean number of

222 events recorded per day that burrows were visited was 4.10 for Blue Petrels and 2.58 for Grey

223 Petrels. For both species the between-burrow variance in the mean number of events per day (SD

2241.73 for Blue Petrels and SD 1.12 for Grey Petrels) was lower than the within-burrow variance (SD

2253.95 for Blue Petrels and SD 1.76 for Grey Petrels), suggesting that the activity captured was

226 relatively uniform across burrows.

Peak activity at Blue Petrel burrows is apparent early in the breeding season, tailing off later in the

activity between them. Generally, we also observed bouts of tidying around the burrow entrance

early in the breeding season at burrows with high activity peaks. Burrows 05 and 20 lack earlycameras performed (burrows 02-21) with few cameras recording right through to the end of the season.

The Grey Petrel dataset was more complete, with the exception of the Spypoint cameras at burrows began during incubation by which point adult attendance at most burrows was relatively uniform. burrows $04,08,12,13$ or 16 , and each of these burrows was only occupied during the first visit. 
244 Chicks were recorded in all other burrows during manual inspections, but the fate of the breeding

245 attempts was sometimes uncertain. For example, burrow 03 was empty when visited on $26^{\text {th }}$

246 October but the camera showed the chick had first emerged when downy some weeks earlier, and

247 had attained full adult plumage when last recorded on the camera on $23^{\text {rd }}$ October. From the

248 cameras we inferred that all chicks in these study burrows fledged successfully, as well as the

249 fledging date from each burrow (Figure 3).

Inferring breeding and non-breeding burrows

252 We were particularly interested in whether the activity signatures from each burrow can be used to 253 infer breeding status of the burrows. From the PCA there is weak evidence that absences tend to be 254 longer during incubation and there are more low-activity days at breeding Grey Petrel burrows than non-breeding burrows (Figure 4). Later in the season during early and late chick-rearing absences are longer at non-breeding than breeding burrows, but when birds are present there is more activity at the burrow entrance of non-breeding burrows while breeding burrows are characterised by low activity (Figure 4).

These apparent differences are also evident in the group means of the predictor variables we used in

LDAs (Table 2). The three LDAs were broadly able to discriminate between breeding and nonpartial time series available (Table 3). 
uncertainty and lower type 1 error (false negatives) when predicting burrow occupancy compared

with using playback. For example, comparing panel a) using a burrowscope to inspect Antarctic Prion assigned 20 burrows as empty and 15 as occupied on the first visit - sensitivity + specificity $=46 \%$. However, we incorrectly identified 11 burrows as empty on first visit which were in fact occupiedtype 1 error $=24 \%$. And we were uncertain about the occupancy of 30 burrows $(39 \%)$ on first visit, 14 of which were subsequently identified as occupied while 16 remained uncertain. Using playback, owing to our inability to distinguish between non-responsive birds in burrows and empty burrows, we could not definitively assign any burrows as empty (Figure 6d). We correctly identified 72 burrows as occupied on first visit-sensitivity $26 \%$-but were uncertain about the status of the remaining 197 burrows (74\%).

There is an important distinction between determining occupancy in individual burrows and estimating overall population-level occupancy. The former is used to measure burrow-specific variables such as breeding status and success. The latter to adjust burrow counts when estimating the number of occupied burrows, either in a sample or in the whole population. We were able to refine population-level estimates of occupancy derived from playback by calibrating the response rate through repeat visits. We estimated overall occupancy in Blue Petrel burrows as $0.56(95 \% \mathrm{Cl}$ : 0.42-0.70) after nine visits to calibrate our sample (Table S1). However, after achieving only 4 repeats for Antarctic Prions there was little flattening of the accumulation curve and the "du Feu" method, possibly erroneously in this case, estimates that all burrows are occupied (Table 4). Through repeated playback population-level occupancy can be estimated. However, while using a 
292 Uncertainty was lowest when using the burrowscope at larger White-headed Petrel burrows. We

293 were able to correctly diagnose 218 of 233 (92\%) burrows on the first visit, but 15 occupied burrows

$294(6 \%)$ were incorrectly diagnosed as empty. Uncertainty was greater with a handheld camera than a

burrowscope (25\% compared with 2\%, Figure 6) but type 1 error was not (Table 4).

296 Comparing methods for determining breeding status and breeding success, it is clear that playback is

297 incompatible with collecting the burrow-level information needed. Even with manual burrow

298 inspection, we were often unsure of breeding status on first visits alone because birds were not

299 manoeuvred to check whether they were incubating eggs in order to avoid undue disturbance.

300 However, by repeating visits through the season, we were able to determine the breeding status of

30196 of $136(70 \%)$ occupied White-headed Petrel burrows and 82 of 101 (82\%) occupied Grey Petrel

302 burrows (Table 5). We estimated breeding success as $0.83(0.75-0.90)$ and $0.77(0.68-0.75)$ for

303 White-headed and Grey Petrels respectively after all visits. The two visits that were made to Blue

304 Petrel burrows were insufficient to estimate breeding success.

305 Occupancy is an inferior metric to breeding status of burrows but is used in one-off survey visits.

306 Through deployments (long and short) of camera traps at burrow entrances we believe it is possible

307 to reliably determine burrow breeding status given a sufficient sample size of known-status burrows

308 from which to model status as a function of nest-level activity. Furthermore, camera traps can

309 substantially reduce uncertainty in estimated breeding success.

\section{Discussion}

312 Conservation assessments focus on the portion of populations that are breeding, i.e. those which

313 carry the reproductive potential of the species (IUCN, 2019). The challenge of determining the size

314 and trends of burrowing-seabird breeding populations when only burrow entrances are visible at the

315 surface is now decades old, yet there has been little research into the activity of seabirds at burrow 
entrances or the relationship between this activity and breeding status and success of individual

burrows. We found that camera traps positioned at burrow entrances were able to collect time

series activity patterns from which we could infer breeding status and breeding success of individual

burrows. Provided the cameras used are fit-for-purpose, camera traps provided higher resolution

data on the number of successful breeding attempts from a sample of burrows than is possible

through burrow inspection.

Despite our relatively low sample size, we were able to discriminate effectively between breeding

type 1 and 2 error rates around inferred breeding status is warranted. LDAs had higher sensitivity Jouventin, 1985). In contrast, non-breeding birds are not bound to a chick and can take longer absences. Non-breeding shearwaters are known to spend up to four times longer at the surface than breeding birds (Bonnaud et al., 2009), consistent with our observation of the highest activity peaks outside non-breeding burrows and the group means from LDAs.

Importantly the ratio of breeding to non-breeding burrows varies in dynamic populations. proportions of immigrant and immature birds which may prospect without attempting to breed. In declining populations experiencing high predation rates prospecting birds can be disproportionately impacted resulting in a higher proportion of occupied burrows supporting breeding birds (Bonnaud but it is difficult with traditional methods which we show are prone to high uncertainty. For future studies we would focus on increasing our sample size to assess whether linear discriminant models 
341 burrow entrance activities are between breeding sites. Calibration might only be necessary at a

342 handful of sites to train LDAs that can be applied elsewhere to new camera trap datasets.

343 Regardless of the eventual reliability of camera trap LDAs for inferring breeding status of burrows,

344 using camera traps in consort with other methods provides valuable information. For example, in

345 the non-breeding burrows we followed, the camera traps revealed high rates of burrow activity but

346 paired with manual inspection we found these burrows were rarely occupied in the daytime.

347 Playback studies suffer from the untested assumption that occupied burrows support breeding birds

348 (Schulz et al., 2006). Camera trap deployments could potentially be used to test this assumption and

349 calibrate playback for use as a rapid assessment method. Additionally, the activity data from camera

350 traps could be used to inform survey design by providing information on peak seasonal activity.

351 Interestingly the early chick rearing LDA from mid-season was best at predicting breeding status of

352 our test burrows. Most surveys focus on the start of the breeding season when birds are most vocal

353 and responsive to playback and burrow inspection causes low disturbance or the end of the

354 breeding season when breeding success can be inferred.

355 Camera traps have a number of potential advantages over traditional survey methods. Playback is

356 only applicable to occupancy estimation, not to studying breeding numbers and success. We have

357 found burrow inspection to be observer biased, its reliability varies according to the quality of the

358 burrow-scope available (Lavers et al., 2019), and it can cause disturbance. The accuracy of estimates

359 of breeding success are also dependent upon the frequency of burrow checks, whereas camera traps

360 can yield precise timings of key events such as fledging or predation. Camera trap studies are less

361 susceptible to personnel bias, and once established can potentially be repeated with relative ease

362 and minimal disturbance. It is unclear how representative an occupancy estimate is when it is based

363 upon data from a single season as is often the case. Occupancy varies between years because some

364 species do not breed annually (Chastel, 2008), and stochastic events make some years more

365 conducive to breeding than others. Adopting methods that can span several breeding seasons with 
little inter-annual bias in data collection will help to uncover some of these important patterns in seabird breeding dynamics.

We recorded several unexpected species and behaviours at cameras with serendipitous benefits.

There is no reliable data on historic seabird populations on Macquarie Island before the impacts of

from the north of the island, however, one individual at a Grey Petrel burrow on North Head, the extreme northern end of Macquarie Island and outside their current breeding range was recorded on our cameras. While these observations highlight the potential of cameras for gathering ecological data, Fischer et al.'s (2017) conclusion that camera traps are unsuitable for studying breeding biology at individual diving-petrel nests also applies in part to our study species. Not all entries and exits are captured by camera traps, and the precise position of the deployed camera can strongly affect what is recorded. Camera traps would, therefore, not be reliable for high resolution behavioural and phenological research such as studying incubation shift duration, and the frequency of chick provisioning.

We did encounter a number of challenges that will need addressing if camera traps are to be 
transforming the ability of monitoring programmes to tag large image datasets (Norouzzadeh et al.,

2018; Willi et al., 2019), but behaviours may still be problematic. We had difficulty differentiating

chicks from adults close to fledging. Only by manually coding images did we develop a familiarity

with individuals which could aid identification. For example, bills of procellariform petrels develop

slowly, and chicks often had noticeably slender bills even close to fledging, but judgements like this

are highly subjective and potentially beyond a classification algorithm or volunteer programme. In

one case it became apparent that two different chicks from adjacent burrows were triggering one

camera. They were at different stages of development and could be readily identified. Ultimately

this allowed us to confirm fledging success and timing from two burrows the status of which was

uncertain based upon manual burrow-inspection, but after the first bird fledged the second

switched burrows temporarily. If this behaviour is common it adds an additional challenge to

determining breeding success. Cameras also needed some maintenance during the season. As well

as battery and SD card replacement, some lenses developed condensation, and vegetation growth

affected false trigger rates and obscured images.

We have shown that camera traps are highly effective at recording nest-level activity and behaviours

of burrowing seabirds, and importantly that breeding status can be modelled as a function of these

activity patterns. Significant investment is needed in terms of financial and human resources to

purchase cameras, deploy and maintain them, calibrate camera data with burrow breeding status,

and to tag images. Many of these investments can be front-loaded and we argue are worthwhile for

long-term monitoring thanks to the benefits camera traps deliver-reduced uncertainty, widely 
$416 \mathrm{JB}$ conceived the ideas and designed methodology; JB and PP collected the data; JB analysed the

417 data; JB led the writing of the manuscript. All authors contributed critically to data interpretation,

418 drafts and gave final approval for publication.

420 Acknowledgements

421 The authors thank Noel Carmichael and Tasmania Parks and Wildlife Service for their support

422 facilitating this project. Thanks to Calum X. Cunningham and Toby D. Travers for suggests for data

423 manipulation and analysis. This study was supported by funding from the Australian Government's

424 National Environmental Science Program through the Threatened Species Recovery Hub, the

425 Australian Antarctic Science program (AAS 4305. JB was supported by a Research Training Program

426 scholarship, an Antarctic Science International Bursary, National Environmental Science Programme

427 Threatened Species Recovery Hub Research Support and a BirdLife Australia Stuart Leslie Bird

428 Research Award. All methods were approved by the University of Queensland Native/Exotic Wildlife

429 and Marine Animals (NEWMA) animal ethics committees (AE29713), the Macquarie Island Research

430 Advisory Group and the Department of Primary Industries, Parks, Water and Environment (TFA

431 17305). Access to Macquarie Island was granted by the Tasmania Parks and Wildlife Service (Access

432 Authority No. 17-18 5).

\section{Data Sharing}

435 Raw data and full code for the analysis are available from the Australian Antarctic Data Centre. 


\section{References}

440

441

Adams, N., 2009. Climate trends at Macquarie Island and expectations of future climate change in the sub-Antarctic. Pap. Proc. R. Soc. Tasman. 143, 1-8.

Barbraud, C., Delord, K., 2006. Population census of blue petrels Halobaena caerulea at Mayes Island, Iles Kerguelen. Antarct. Sci. 18, 199-204. https://doi.org/10.1017/S095410200600023X

Barbraud, C., Delord, K., Marteau, C., Weimerskirch, H., 2009. Estimates of population size of whitechinned petrels and grey petrels at Kerguelen Islands and sensitivity to fisheries. Anim. Conserv. $12,258-265$.

Barrett, R.T., Chapdelaine, G., Anker-Nilssen, T., Mosbech, A., Montevecchi, W.A., Reid, J.B., Veit, R.R., 2006. Seabird numbers and prey consumption in the North Atlantic. ICES J. Mar. Sci. 63, 1145-1158. https://doi.org/10.1016/j.icesjms.2006.04.004

Berrow, S.D., 2000. The use of acoustics to monitor burrow-nesting white-chinned petrels Procellaria aequinoctialis at Bird Island, South Georgia. Polar Biol. 23, 575-579.

Bird, J.P., Woodworth, B.K., Fuller, R.A., Shaw, J.D., submitted. Uncertainty in population estimates: a meta-analysis for petrels. Ecol. Solut. Evid.

BirdLife International, 2018. State of the world's birds: taking the pulse of the planet. Cambridge, UK: BirdLife International.

Bonnaud, E., Bourgeois, K., Vidal, E., Legrand, J., Le Corre, M., 2009. How can the Yelkouan shearwater survive feral cat predation? A meta-population structure as a solution? Popul. Ecol. 51, 261-270. https://doi.org/10.1007/s10144-008-0134-0

Brothers, N., Bone, C., 2008. The response of burrow-nesting petrels and other vulnerable bird species to vertebrate pest management and climate change on sub-Antarctic Macquarie Island, in: Papers and Proceedings of the Royal Society of Tasmania. pp. 123-148.

Brothers, N.P., 1984. Breeding, Distribution and Status of Burrow-nesting Petrels at Macqaurie Island. Aust. Wildl. Res. 11, 113-131. 
465 Carey, M.J., 2009. The effects of investigator disturbance on procellariiform seabirds: a review. N.Z.

466

467

468

469

470

471

472

473

474

475

476

477

478

J. Zool. 36, 367-377.

Carlile, N., Priddel, D., Reid, T., Fullagar, P., 2019. Flesh-footed shearwater decline on Lord Howe: Rebuttal to Lavers et al. 2019. Glob. Ecol. Conserv. 20, e00794. https://doi.org/10.1016/j.gecco.2019.e00794

Catry, P., Campos, A., Segurado, P., Silva, M., Strange, I., 2003. Population census and nesting habitat selection of thin-billed prion Pachyptila belcheri on New Island, Falkland Islands. Polar Biol. 26, 202-207.

Chastel, O., 2008. Influence of reproductive success on breeding frequency in four southern petrels. Ibis 137, 360-363. https://doi.org/10.1111/j.1474-919X.1995.tb08033.x

Chaurand, T., Weimerskirch, H., 1994. The regular alternation of short and long foraging trips in the blue petrel Halobaena caerulea: a previously undescribed strategy of food provisioning in a pelagic seabird. J. Anim. Ecol. 275-282.

Croxall, J.P., Butchart, S.H., Lascelles, B.E.N., Stattersfield, A.J., Sullivan, B.E.N., Symes, A., Taylor, P., 2012. Seabird conservation status, threats and priority actions: a global assessment. Bird Conserv. Int. 22, 1-34.

Croxall, J.P., Ricketts, C., Prince, P.A., 1984. Impact of seabirds on marine resources, especially krill, of South Georgia waters, in: Seabird Energetics. Springer, pp. 285-317.

Danckwerts, D.K., McQuaid, C.D., Jaeger, A., McGregor, G.K., Dwight, R., Le Corre, M., Jaquemet, S., 2014. Biomass consumption by breeding seabirds in the western Indian Ocean: indirect interactions with fisheries and implications for management. ICES J. Mar. Sci. 71, 2589-2598. https://doi.org/10.1093/icesjms/fsu093

Dias, M.P., Martin, R., Pearmain, E.J., Burfield, I.J., Small, C., Phillips, R.A., Yates, O., Lascelles, B., Borboroglu, P.G., Croxall, J.P., 2019. Threats to seabirds: A global assessment. Biol. Conserv. 237, 525-537. https://doi.org/10.1016/j.biocon.2019.06.033 
490

491

492

493

494

Dilley, B.J., Davies, D., Schramm, M., Connan, M., Ryan, P.G., 2017. The distribution and abundance of Blue Petrels (Halobaena caerulea) breeding at subantarctic Marion Island. Emu-Austral Ornithol. 1-11.

du Feu, C., Hounsome, M., Spence, I., 1983. A single-session mark/recapture method of population estimation. Ringing Migr. 4, 211-226. https://doi.org/10.1080/03078698.1983.9673809

Edney, A.J., Wood, M.J., 2020. Applications of digital imaging and analysis in seabird monitoring and research. Ibis n/a. https://doi.org/10.1111/ibi.12871

Fischer, J., Debski, I., Taylor, G., Wittmer, H., 2017. Assessing the suitability of non-invasive methods to monitor interspecific interactions and breeding biology of the South Georgian diving petrel (Pelecanoides georgicus). Notornis 64, 13-20.

Graham, N.A.J., Wilson, S.K., Carr, P., Hoey, A.S., Jennings, S., MacNeil, M.A., 2018. Seabirds enhance coral reef productivity and functioning in the absence of invasive rats. Nature $559,250-253$. https://doi.org/10.1038/s41586-018-0202-3

Hill, A.P., Davies, A., Prince, P., Snaddon, J.L., Doncaster, C.P., Rogers, A., 2019. Leveraging conservation action with open-source hardware. Conserv. Lett. 12, e12661. https://doi.org/10.1111/conl.12661

IUCN, 2019. Guidelines for Using the IUCN Red List Categories and Criteria. Version 13. Prepared by the Standards and Petitions Subcommittee. Downloadable from http://www.iucnredlist.org/documents/RedListGuidelines.pdf.

Jones, E., 1980. A survey of burrow-nesting petrels at Macquarie Island based upon remains left by predators. Notornis 27, 11-20.

Jouventin, 1985. Comparative biology of the burrowing petrels of the Crozet Islands. Notornis 32, $157-220$.

Kuhn, M., 2008. Building Predictive Models in $R$ Using the caret Package. J. Stat. Softw. 28. https://doi.org/10.18637/jss.v028.i05 
515 Lavers, J.L., Hutton, I., Bond, A.L., 2019. Changes in technology and imperfect detection of nest contents impedes reliable estimates of population trends in burrowing seabirds. Glob. Ecol. Conserv. 17, e00579. https://doi.org/10.1016/j.gecco.2019.e00579

Lê, S., Josse, J., Husson, F., 2008. FactoMineR: A Package for Multivariate Analysis. J. Stat. Softw. 25, 1-18. https://doi.org/10.18637/jss.v025.i01

Norouzzadeh, M.S., Nguyen, A., Kosmala, M., Swanson, A., Palmer, M.S., Packer, C., Clune, J., 2018. Automatically identifying, counting, and describing wild animals in camera-trap images with deep learning. Proc. Natl. Acad. Sci. 115, E5716-E5725.

R Core Team, 2020. R: A language and environment for statistical computing. R Found. Stat. Comput.

Perkins, A.J., Bingham, C.J., Bolton, M., 2018. Testing the use of infra-red video cameras to census a Proc. R. Soc. Tasman. 141, 67-81. Vienna Austria URL HttpswwwR-Proj. for Storm Petrels Hydrobates pelagicus. Bird Study 45, 302-312. https://doi.org/10.1080/00063659809461101 
540 Rodríguez, A., Arcos, J.M., Bretagnolle, V., Dias, M.P., Holmes, N.D., Louzao, M., Provencher, J.,

Raine, A.F., Ramírez, F., Rodríguez, B., Ronconi, R.A., Taylor, R.S., Bonnaud, E., Borrelle, S.B.,

Cortés, V., Descamps, S., Friesen, V.L., Genovart, M., Hedd, A., Hodum, P., Humphries,

Votier, S.C., Wanless, R.M., Woehler, E., Chiaradia, A., 2019. Future Directions in https://doi.org/10.3389/fmars.2019.00094

Ryan, P.G., Dorse, C., Hilton, G.M., 2006. The conservation status of the spectacled petrel Procellaria conspicillata. Biol. Conserv. 131, 575-583. https://doi.org/10.1016/j.biocon.2006.03.004

Schulz, M., Robinson, S., Gales, R., 2006. Breeding of the Grey Petrel (Procellaria cinerea) on Macquarie Island: population size and nesting habitat. Emu 105, 323-329. https://doi.org/10.1071/MU04058

Sekercioglu, C.H., 2006. Increasing awareness of avian ecological function. Trends Ecol. Evol. 21, 464-471. https://doi.org/10.1016/j.tree.2006.05.007

Sinclair, J.C., 1981. Techniques for observing subantarctic burrowing petrels at the nest. Mar. Ornithol. 9, 67-72.

Soanes, L.M., Thomas, R.J., Bolton, M., 2012. Evaluation of field and analytical methods for estimating the population size of burrow-nesting seabirds from playback surveys. Bird Study 59, 353-357. https://doi.org/10.1080/00063657.2012.695334

Springer, K., 2016. Methodology and challenges of a complex multi-species eradication in the subAntarctic and immediate effects of invasive species removal. N. Z. J. Ecol. 40, 273.

562 Venables, W.N., Ripley, B.D., 2002. Modern Applied Statistics with S, Fourth. ed. Springer, New York. 563 Wearn, O.R., Glover-Kapfer, P., 2019. Snap happy: camera traps are an effective sampling tool when compared with alternative methods. R. Soc. Open Sci. 6, 181748. 
566 Whitehead, A.L., Lyver, P.O., Jones, C.J., Bellingham, P.J., MacLeod, C.J., Coleman, M., Karl, B.J., of breeding populations of a burrowing seabird, the grey-faced petrel (Pterodroma macroptera gouldi) in New Zealand. Biol. Conserv. 169, 109-116.

Wickham, H., Averick, M., Bryan, J., Chang, W., McGowan, L.D., François, R., Grolemund, G., Hayes, 2019. Welcome to the Tidyverse. J. Open Source Softw. 4, 1686. 
bioRxiv preprint doi: https://doi.org/10.1101/2021.04.08.438875; this version posted April 10, 2021. The copyright holder for this preprint (which

was not certified by peer review) is the author/funder, who has granted bioRxiv a license to display the preprint in perpetuity. It is made available under aCC-BY-NC-ND 4.0 International license.

579 Table 1: Performance metrics for Reconyx and SpyPoint cameras positioned at seabird burrow

580 entrances.

\begin{tabular}{llccccccc}
\hline & & $\mathbf{n}$ & target:false & \multicolumn{2}{c}{ proportion of trap } & \multicolumn{3}{c}{ entries:exits } \\
make & species & burrows & triggers & nights $>0$ images & min & max & SD \\
\hline Reconyx & All & 13 & 18.86 & 0.64 & 0.20 & 1.56 & 0.41 \\
Reconyx & Grey Petrel & 12 & 19.89 & 0.63 & 0.20 & 1.56 & 0.41 \\
Reconyx & Blue Petrel & 1 & 6.39 & 0.85 & 0.96 & 0.96 & 0.00 \\
\hline SpyPoint & All & 24 & 1.30 & 0.39 & 0.52 & 5.67 & 1.09 \\
SpyPoint & Grey Petrel & 4 & 3.08 & 0.33 & 0.60 & 1.07 & 0.17 \\
SpyPoint & Blue Petrel & 20 & 0.95 & 0.40 & 0.52 & 5.67 & 1.16 \\
\hline
\end{tabular}


bioRxiv preprint doi: https://doi.org/10.1101/2021.04.08.438875; this version posted April 10, 2021. The copyright holder for this preprint (which

was not certified by peer review) is the author/funder, who has granted bioRxiv a license to display the preprint in perpetuity. It is made available under aCC-BY-NC-ND 4.0 International license.

581 Table 2: Group means for variables derived from adult activity at Grey Petrel burrow entrances that

582 were used in Linear Discriminant Analysis, and their contributions to the first linear discriminant.

\begin{tabular}{llccc}
\hline stage & variable & breeding & non-breeding & LD1 \\
\hline \multirow{2}{*}{ incubation } & absences & 1.87 & 1.70 & -0.09 \\
& high activity & 0.05 & 0.10 & 13.63 \\
& low activity & 0.59 & 0.28 & -12.30 \\
\hline \multirow{2}{*}{ early chick- } & absences & 1.89 & 2.55 & 0.71 \\
rearing & high activity & 0.03 & 0.18 & 9.32 \\
& low activity & 0.59 & 0.38 & -2.65 \\
\hline \multirow{2}{*}{ late chick-rearing } & high activity & 0.02 & 0.04 & -11.69 \\
& low activity & 0.34 & 0.20 & 5.53 \\
\hline
\end{tabular}


bioRxiv preprint doi: https://doi.org/10.1101/2021.04.08.438875; this version posted April 10, 2021. The copyright holder for this preprint (which

was not certified by peer review) is the author/funder, who has granted bioRxiv a license to display the preprint in perpetuity. It is made available under aCC-BY-NC-ND 4.0 International license.

583 Table 3: Predicted breeding status in two known-status test burrows from Linear Discriminant

584 Analyses.

\section{prediction}

\begin{tabular}{clcc} 
& LDA model & breeding & non-breeding \\
\hline GP-NH-10: & incubation & - & - \\
breeding & early chick-rearing & 0.9995 & 0.0005 \\
& late-chick-rearing & 0.9986 & 0.0014 \\
\hline GP-NH-13: & incubation & 1.0000 & $<0.0001$ \\
non-breeding & early chick-rearing & 0.0911 & 0.9089 \\
& late-chick-rearing & 0.9998 & 0.0002 \\
\hline
\end{tabular}


bioRxiv preprint doi: https://doi.org/10.1101/2021.04.08.438875; this version posted April 10, 2021. The copyright holder for this preprint (which

was not certified by peer review) is the author/funder, who has granted bioRxiv a license to display the preprint in perpetuity. It is made available under aCC-BY-NC-ND 4.0 International license.

585 Table 4: Burrow occupancy in different species estimated using different survey methods.

586 Occupancy and confidence intervals are calculated from diagnosed burrows only. Type 1 error was

587 not calculated for playback because occupancy status of all non-responsive burrows was listed as

588 'uncertain' owing to the possibility of non-responsive birds.

White-headed

\begin{tabular}{|c|c|c|c|c|c|}
\hline Method & Parameter & Antarctic Prion & Blue Petrel & Petrel & Grey Petrel \\
\hline Playback* & Occupancy $( \pm 95 \% \mathrm{Cl})$ & $1.00(0.55-1.00)$ & $0.56(0.42-0.70)$ & - & - \\
\hline \multirow[t]{2}{*}{ Burrowscope } & Occupancy $( \pm 95 \% \mathrm{Cl})$ & $0.32(0.19-0.46)$ & $0.32(0.26-0.39)$ & $0.50(0.43-0.56)$ & - \\
\hline & Type 1 error & 0.24 & 0.06 & 0.06 & - \\
\hline Handheld & Occupancy $( \pm 95 \% \mathrm{Cl})$ & - & - & $0.66(0.59-0.73)$ & - \\
\hline camera & Type 1 error & - & - & 0.02 & - \\
\hline Combined & Occupancy $( \pm 95 \% \mathrm{Cl})$ & $0.67(0.55-0.79)$ & $0.40(0.33-0.47)$ & $0.59(0.53-0.66)$ & $0.42(0.36-0.49)$ \\
\hline
\end{tabular}


bioRxiv preprint doi: https://doi.org/10.1101/2021.04.08.438875; this version posted April 10, 2021. The copyright holder for this preprint (which

was not certified by peer review) is the author/funder, who has granted bioRxiv a license to display the preprint in perpetuity. It is made available under aCC-BY-NC-ND 4.0 International license.

589 Table 5: Inferred breeding status of seabird burrows based upon initial, and follow-up visits.

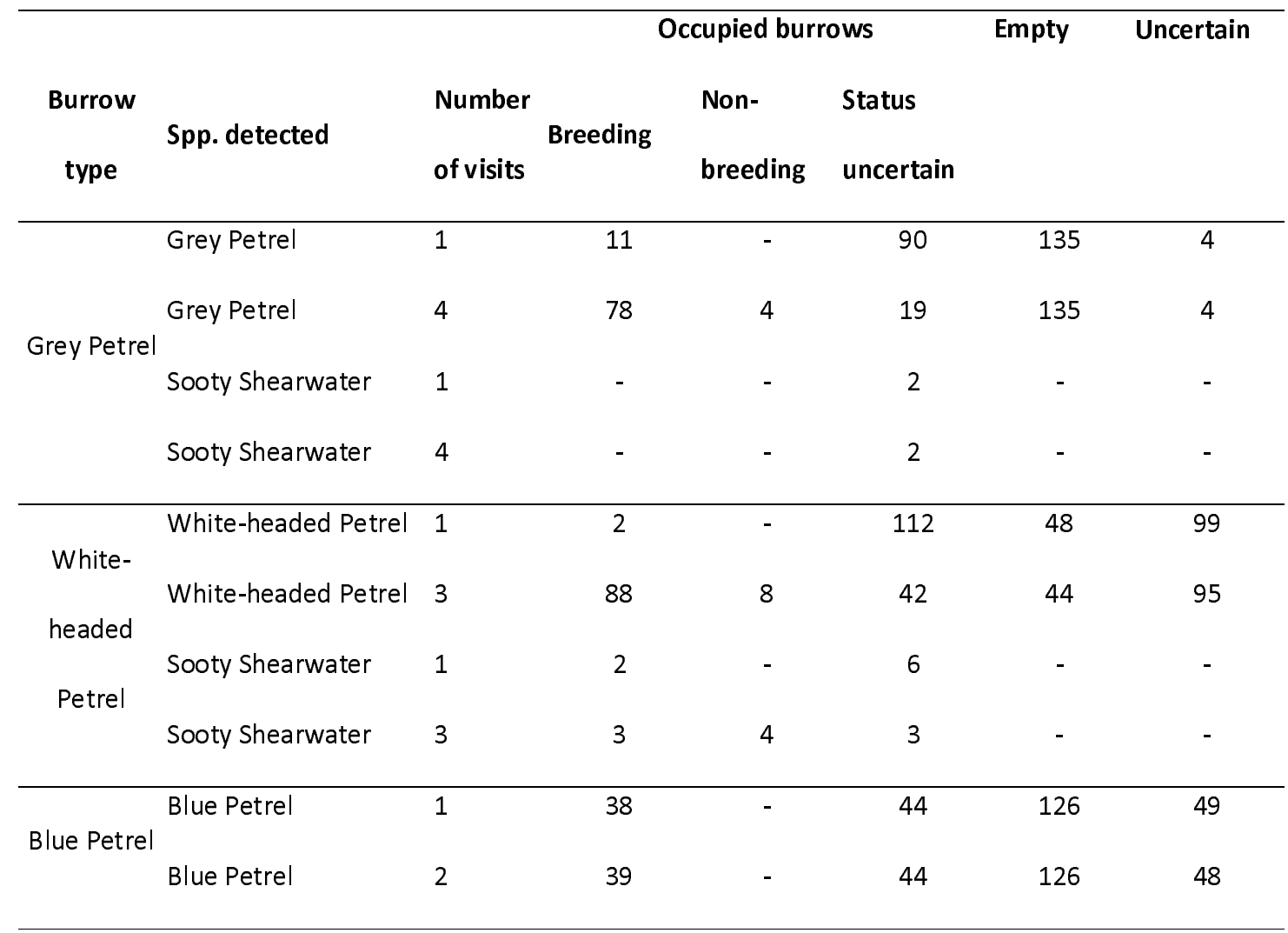

590 
bioRxiv preprint doi: https://doi.org/10.1101/2021.04.08.438875; this version posted April 10, 2021. The copyright holder for this preprint (which was not certified by peer review) is the author/funder, who has granted bioRxiv a license to display the preprint in perpetuity. It is made available under aCC-BY-NC-ND 4.0 International license.

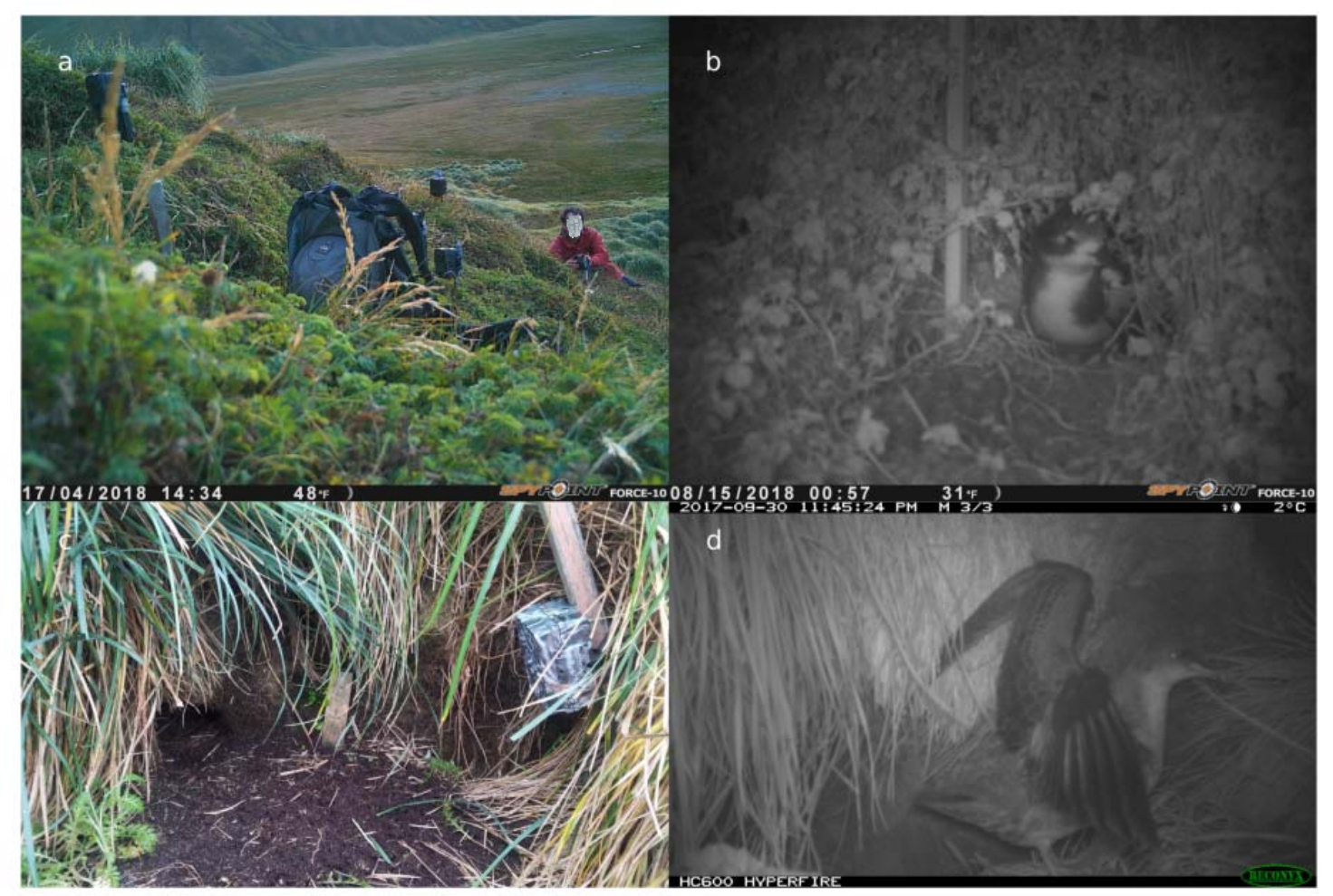

Figure 1: Camera trap set-up and results: a) checking Spypoint cameras in a Blue Petrel colony, b) a Blue Petrel emerging from its burrow, c) a Recconyx camera outside a Grey Petrel burrow, and d) a Grey Petrel chick close to fledging exercising outside its burrow. 
bioRxiv preprint doi: https://doi.org/10.1101/2021.04.08.438875; this version posted April 10, 2021. The copyright holder for this preprint (which was not certified by peer review) is the author/funder, who has granted bioRxiv a license to display the preprint in perpetuity. It is made available under aCC-BY-NC-ND 4.0 International license.

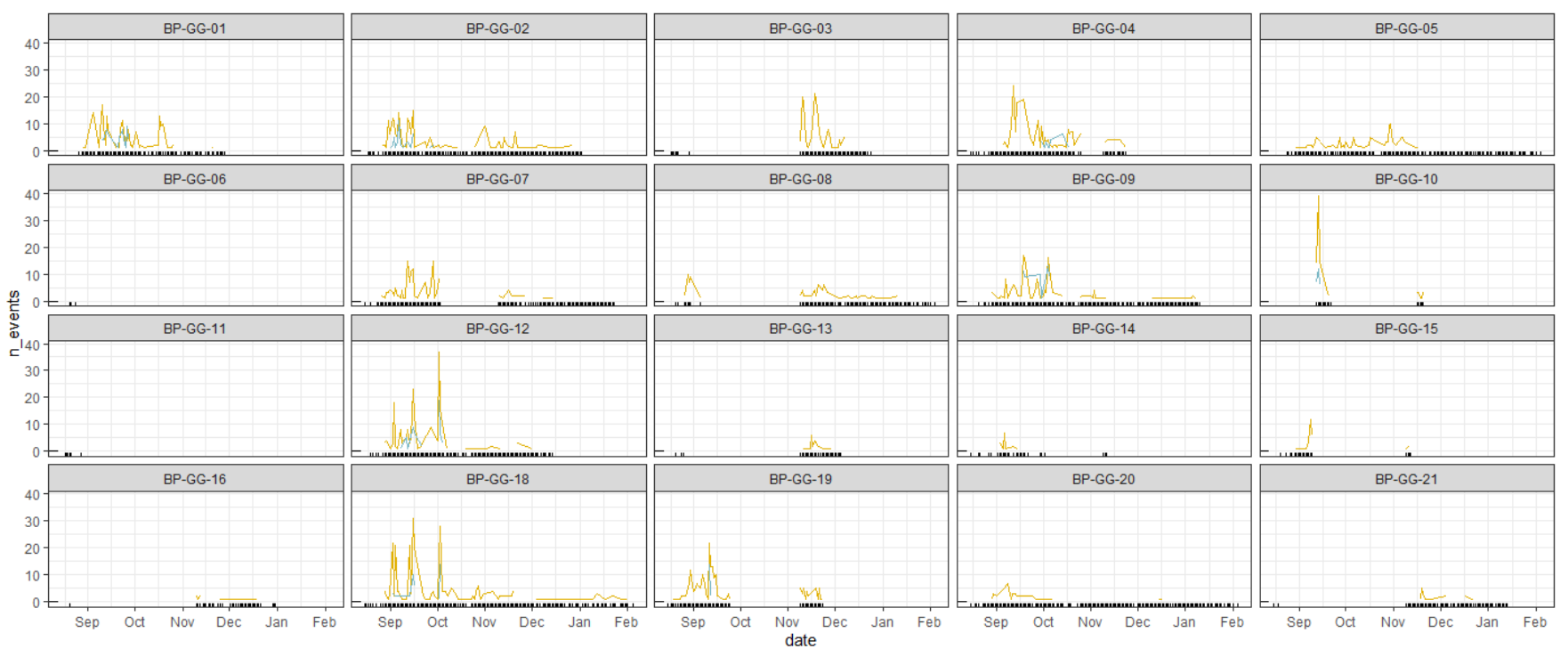

Figure 2: Combined entries and exits (yellow) and tidying events (blue) recorded at Blue Petrel burrow entrances during the breeding season. Rug plots show the days on which any images were captured, i.e. the camera was known to be functioning correctly. 
bioRxiv preprint doi: https://doi.org/10.1101/2021.04.08.438875; this version posted April 10, 2021. The copyright holder for this preprint (which was not certified by peer review) is the author/funder, who has granted bioRxiv a license to display the preprint in perpetuity. It is made available under aCC-BY-NC-ND 4.0 International license.

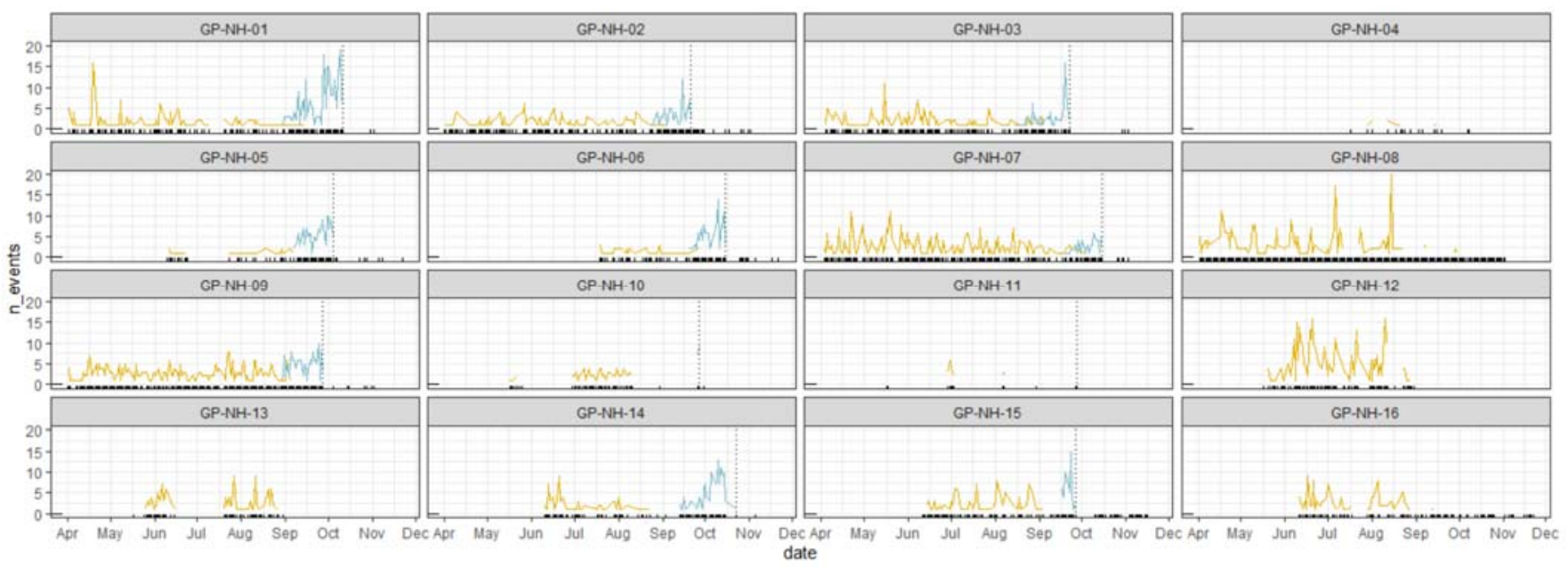

Figure 3: Total number of events featuring adults (yellow) and chicks (blue) at Grey Petrel burrow entrances during the breeding season. Rug plots show the days on which any images were captured, i.e. the camera was known to be functioning correctly. Vertical dotted lines represent inferred fledging dates. 

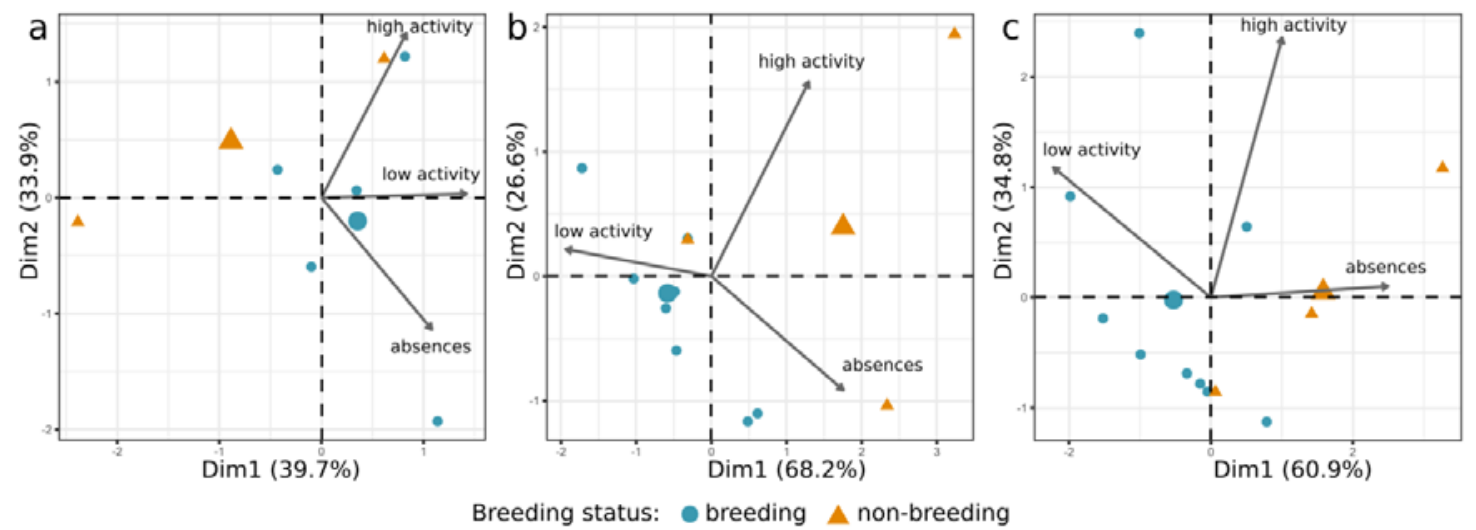

Figure 4: Principal Component Analyses of variables derived from adult activity data captured by cameras at Grey Petrel burrow entrances. Plot a) is activity data from during incubation, $b$ ) is from early chick-rearing and c) is from late chick-rearing. The larger symbols represent group means. 
bioRxiv preprint doi: https://doi.org/10.1101/2021.04.08.438875; this version posted April 10, 2021. The copyright holder for this preprint (which was not certified by peer review) is the author/funder, who has granted bioRxiv a license to display the preprint in perpetuity. It is made available under aCC-BY-NC-ND 4.0 International license.

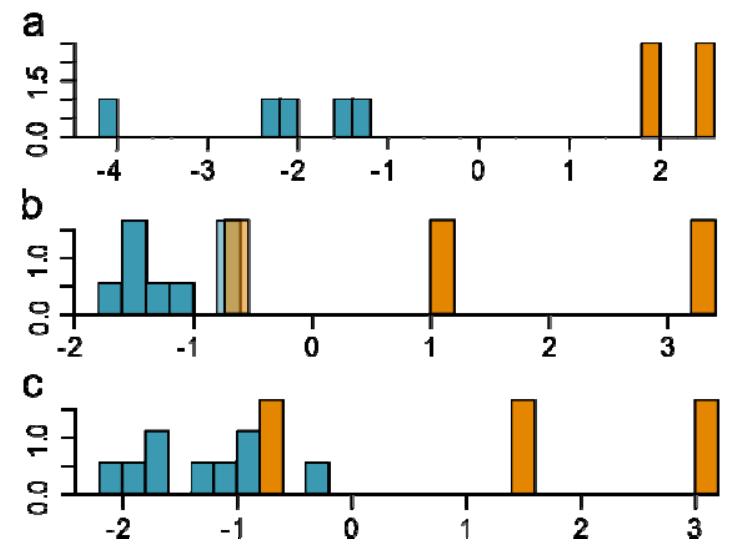

Figure 5: Linear Discriminant Analyses of breeding and non-breeding Grey Petrel burrows based upon variables derived from adult activity at burrow entrances. Model a) is activity data from during incubation, $b$ ) is from early chick-rearing and $c$ ) is from late chick-rearing. Breeding burrows are depicted in blue, non-breeding in orange. 


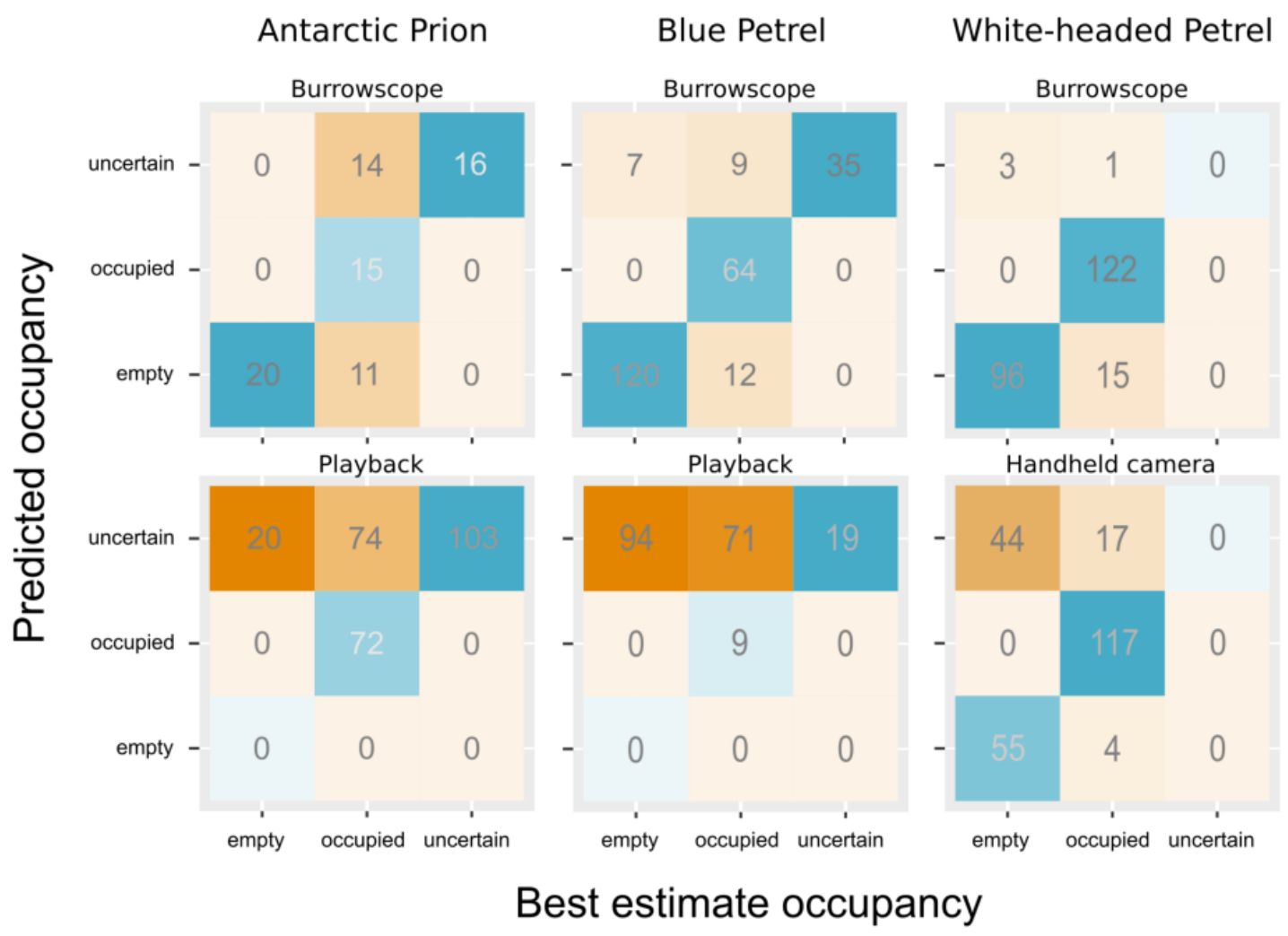

Figure 6: Confusion matrices of predicted versus observed occupancy from different methods. Predicted occupancy is based upon the first visit only, equivalent to one-off occupancy estimation feasible in most surveys. Observed occupancy is based upon all methods and all visits. Predicted = observed is shaded green, predicted $\neq$ observed is shaded yellow, with higher matching or mismatching ratios shaded darker. 